\title{
Effects of Peer Feedback on EFL Student Writers at Different Levels of English Proficiency: A Japanese Context
}

Taeko Kamimura

\begin{abstract}
A study was conducted to explore the nature and effectiveness of peer feedback in EFL writing classrooms. High- and low-proficient Japanese EFL learners participated in the study where they exchanged comments with peers after receiving training in peer feedback. The two groups were compared in terms of their preand post-tests, original drafts and rewrites, peer comments, and responses to the comments. It was found that peer feedback had overall positive effects on the compositions for both the high-and low-proficient students, with different patterns observed in the relationship between the comments and revisions that characterized the two groups.
\end{abstract}

Cette étude porte sur la nature et l'efficacité de la rétroaction par les pairs dans les cours de rédaction en ALE. Des apprenants japonais en ALE (un groupe à habileté élevée, un autre à habileté basse) ont participé à l'étude. Après avoir reçu une formation en rétroaction, les apprenants ont échangé des commentaires avec leurs pairs. Une comparaison des deux groupes a été dressée selon plusieurs critères : résultats aux pré- et post-tests; brouillons et versions subséquentes; commentaires par les pairs, et réactions aux commentaires. Nous avons trouvé que la rétroaction par les pairs avait des effets positifs globaux pour tous les apprenants, mais que le rapport entre les commentaires et les textes révisés était différent d'un groupe à l'autre.

\section{Introduction}

Peer feedback has been recognized as an essential component in the processoriented teaching of writing in English as a first language (L1). The beneficial effects of using peer feedback have been widely discussed in L1 writing literature. Elbow (1981), for example, argued that peer interactions foster students' awareness of audience and give a communicative purpose to a writing activity, and Kroll and Vann (1981) contended that peer reviews help student writers recognize their own egocentric point of view in writing. Several other L1 researchers have empirically proved the positive effects of peer feedback on students' compositions. Clifford (1981), for example, reported that collaborative peer work among college students resulted in significant gains on their holistically scored compositions. Gere and Stevens 
(1985) closely observed how 5th, 8th, and 12th graders engaged themselves in peer feedback sessions; they found that these students reacted as active readers in their peer interactions and gave specific responses that focused on clarifying and constructing meaning in the text. Nystrand (1986) demonstrated that peer review was also effective in college freshman writing classrooms when it was conducted in a collaborative yet critical manner. Nystrand $(1984,1986)$ maintained that peer feedback could function as an effective writing pedagogical tool if proper preparation and guidelines were provided to students in advance. Spear (1988) and Tompkins (1990) showed a series of questions that could be used as guidelines for generating beneficial peer responses from students engaged in peer feedback activities.

Influenced by the shift in pedagogical focus from product to process in the L1 writing field, L2 writing researchers and teachers also began to pay considerable attention to peer feedback. Keh (1990), for example, recommended the use of peer feedback as a useful pedagogical activity in L2 writing classrooms and summarized the benefits succinctly as follows.

There are several advantages given for using peer feedback... It is said to save teachers' time on certain tasks, freeing them for more helpful instruction. Feedback is considered to be more at the learner's own level of development. Learners can gain a greater sense of audience with several readers (i.e., readers other than the teacher). The reader learns more about writing through critically reading others' papers. (p. 296)

On the other hand, in the same year that Keh's paper was published, Leki (1990), although acknowledging the benefits of peer feedback, pointed out potential problems inherent in peer responding in ESL writing classes as follows.

Teachers who have used peer responding are generally convinced of its usefulness, but many are unaware of the special problems ESL writers and readers face when asked to comment on partners' writing. These problems stem partly from ESL students' lack of experience in using techniques like peer responding and partly from the varying rhetorical expectations that readers from other cultures bring to a text. (p. 5)

A number of L2 studies have been undertaken to investigate empirically the validity of using peer feedback in L2 writing classes. These studies can be roughly classified into four groups according to their research focuses: studies on (a) the relative effectiveness of peer feedback and teacher feedback, (b) the effect of peer feedback on students' subsequent revisions, (c) the nature of peer interaction, and (c) the students' attitudes toward peer feedback. Unlike the situation in L1 composition research, L2 studies in these four areas have all presented conflicting results. 
The first group of studies compared the relative effectiveness of peers' feedback and teachers' feedback. Chaudron (1984), for example, examined whether advanced college ESL students' revised essays showed greater improvement when they received peers' feedback than when they received teachers' feedback and found that neither of the two types of feedback contributed to qualitative improvement in writing. Hedgcock and Lefkowitz (1992) reported a slightly more positive effect of peer feedback in their analysis of essays written by college students learning French as a foreign language, arguing that the peer review procedure did not yield "astoundingly better L2 compositions," but the procedure did not, "as some FL instructors might fear, result in grammatically inferior writing" (p. 264). Nelson and Murphy (1993) provided a more favorable view of peer feedback in their study in which low-intermediate ESL students' responses to their peers' drafts were compared with those of trained raters. Their students, although less proficient in English, responded similarly to the trained raters in that both could identify macro-level problems with organization, development, and topic sentence, whereas the latter spotted more problems concerning cohesion. Caulk (1994) compared her own written comments as a writing teacher and those of ESL students (ranging from intermediate to advanced proficiency). She found most of the students' comments valid, but only a small portion of her suggestions were mentioned by the students. The students' advice tended to be more specific and geared toward a particular problem, whereas her suggestions were more generalizable and took the whole piece of writing into consideration. Thus Caulk claimed that both types of feedback play complementary roles in developing students' writing abilities. Tsui and $\mathrm{Ng}$ (2000) also underscored the differential functions of peer and teacher feedback in their comparative study of peers' and teachers' comments in an EFL secondary school context. They maintained that although teachers' comments led to more revisions than peer responses, the students' comments had specific roles in fostering their sense of authentic audience and ownership of text and contributed to raising their awareness of both strengths and weaknesses in their own compositions.

Another line of research has been attempted to probe the effect of peer feedback on students' subsequent revision, and again the research yielded mixed findings. Connor and Asenavage (1994) compared the amount and types of revisions made by students enrolled in an ESL freshman writing class. Their finding was "disappointing": only a small number of revisions $(5 \%)$ resulted from peer responses. Tsui and $\mathrm{Ng}(2000)$ also found that peers' comments induced less substantial revisions than teachers' comments. Although recognizing the importance of peer feedback, Mendonça and Johnson (1994) pointed out that their advanced ESL students incorporated peers' suggestions into their revisions only selectively, according to their decisions on the validity of each comment. Other studies, however, revealed 
that whether peer feedback results in substantial revisions depends on the nature of interaction in peer reviews. Nelson and Murphy (1993), for example, found that "when student writers interacted in a cooperative manner, they were more likely to use the peers' suggestions" (p. 149); on the other hand, when they interacted in a defensive manner or when they did not interact at all, they were less likely to incorporate peers' suggestions into their revisions. Villamil and de Guerrero's study (1998) also demonstrated that their intermediate college ESL students interacted collaboratively, and this generated extensive use of peers' suggestions into their later drafts.

Such a focus on the nature of peer interactions and their effect on writing improvement has motivated other groups of L2 studies in peer feedback. Mangelsdorf and Schlumberger (1992) analyzed the stances taken by students in ESL freshman classes when they provided comments on other ESL students' essays. The authors found that most of their ESL students took a "prescriptive stance," in which the students expected the text to follow a preconceived form rather than a more productive "collaborative stance," which enabled the students to see the text from the writer's point of view. Nelson and Murphy (1992) presented an even more negative picture of peer review sessions of ESL students. The students in their study demonstrated unfavorable social relationships controlled by a student who manifested particularly aggressive and attacking behavior. However, in their in-depth analysis of intermediate college ESL students' interactions in peer feedback, de Guerrero and Villamil (1994) contended that asymmetrical relationships between the reader and writer are not necessarily detrimental if the "selfregulated" (i.e., capable of independent problem-solving) reader can assist the "other-regulated" (i.e., guided by a peer) with his or her revision processes. Unlike Nelson and Murphy (1992), Lockhart and Ng (1995) reported that they found no instance of aggressive behavior. The ESL college students in their study exhibited a variety of stances, among which the "collaborative stance" was most successful, because this stance in the "discovery mode" facilitates negotiation between the reader and writer; thus it allows the writer to reflect on the meanings in the text and to discover new ideas.

All these studies on the social nature of peer reviews suggest that guided training is a key to realizing collaborative peer interactions. Connor and Asenavage (1994) explained that one of the reasons for their students' reluctance to incorporate peers' suggestions into their revisions was a lack of experience in peer review on the part of the students and called for further studies in providing ESL students with training in peer feedback. An example of these studies is one in which Stanley (1992) provided a class of college ESL students with extensive coaching with a focus on "familiarizing students with the genre of the student essay and introducing students to the task of making effective responses to each other" (p. 221). The coaching considerably improved the quality of peer interactions, inducing a number of 
specific and focused responses to the peers' compositions. Similar findings were obtained by Berg (1999b), who investigated the effects of training in peer response on college ESL students' revisions. Berg trained the students for an extensive period by using the systematic program she developed to promote effective peer feedback. She found that compared with their untrained counterparts, the trained students made a greater number of meaning-based revisions as opposed to surface-level ones, and that their final drafts showed overall improvement in quality over the initial drafts.

The fourth group of studies centered on L2 students' perceptions of and attitudes toward peer feedback. In this category again, findings vary from one study to another. Some surveys report that ESL students appreciate peer feedback as a beneficial activity to enhance their writing abilities (Keh, 1990; Rothschild \& Klingenberg, 1990; Tsui \& Ng, 2000). Those who argued for the effectiveness of peer feedback maintained that if proper preliminary training is provided, ESL students can provide specific and meaning-based suggestions for revision even though English is not their native language but the language they are learning (Berg, 1999b; Liu \& Hansen, 2002), and the students thus find each other's peer reviews highly beneficial for the improvement of their subsequent drafts. Other studies, however, indicated that students prefer teacher feedback to peer feedback (Zhang, 1995; Nelson \& Carson, 1998) and that they are more likely to accept teachers' comments for revisions than those of peers (Connor \& Asenavage, 1994; Nelson \& Carson). Zhang is particularly skeptical about the affective advantage of peer feedback over teacher feedback for L2 learners, arguing that his findings "pose a serious challenge to the aggregate validity of the affective arguments for giving a preeminent role to peer feedback in the ESL writing process" (p. 216). Those who doubt the effectiveness of peer feedback also point out that it is often counterproductive for students who come from non-Western cultural backgrounds and rhetorical traditions, with their emphasis on group consensus rather than on verbal negotiation (Allaei \& Connor, 1990). Several studies reported that Chinese and Japanese students tended to assume negative views of peer feedback (Mangelsdorf, 1992; Zhang, 1995) and often failed to participate actively in peer review sessions (Allaei \& Connor; Carson \& Nelson, 1996; Nelson \& Carson). However, recording students' journals entries, Nagasaka (2000) found that Japanese EFL students showed a favorable attitude toward peer feedback.

In sum, a growing number of studies in peer feedback have been undertaken in the ESL context (see Liu \& Hansen, 2002, for a comprehensive review). However, they have presented controversial findings, and we have not yet reached consensus on the efficacy of peer feedback. The number of peer feedback studies undertaken in the EFL context is small, and even fewer are studies conducted in the Japanese context where students with a great range of English proficiency levels study in the non-Western rhetorical tradi- 
tion. The present study is one of the first attempts to probe the nature and effectiveness of peer feedback in Japanese EFL writing classrooms. The focus of the study is to examine whether peer feedback, when given with preliminary training, can work for Japanese university EFL students with differing levels of English proficiency; and if so, what differential effects can be observed depending on the students' proficiency levels.

\section{Research Questions}

The following research questions guided the present study.

1. Does peer feedback have different effects on the writing performance of Japanese university EFL students with high- and low-English proficiency?

2. Does peer feedback have different effects on the revisions made by the two groups?

3. Are there any differences between the peer comments made by the two groups?

4. Are there any conspicuous patterns in the relationship between the comments and revisions that characterize the two groups?

\section{Procedure}

\section{Participants}

Two classes of Japanese university EFL students, A Class and B Class, participated in the present study. Each class consisted of 12 Japanese university freshmen who majored in English. The students' levels of English proficiency were measured by a commercially available proficiency test called General Tests of English Language Proficiency (G-TELP, Level 3 of the test of used in the present study, with Level 1 being the highest and Level 4 the lowest). This test comprised three sections (listening, grammar and vocabulary, and reading) with a total mark of 300 points. The average score for A Class was 232.08, and that for B Class was 183.33. A $t$-test revealed a significant difference in score of G-TELP between the two classes $(t=10.60, p<.01)$. Thus in the present study, the students in A Class and B Class were regarded as high-proficient and low-proficient respectively.

\section{Research Design}

Figure 1 shows the research design for the present study. A total of five sessions were set up for the research. The five sessions had different purposes and were conducted as described below. Both A Class and B Class underwent these five sessions according to the same procedure.

\section{The first session}

In the first session, as a pre-test the students in both A Class and B Class wrote an argumentative essay in 40 minutes without using a dictionary. In 
this pre-test, the students were told to argue whether television is harmful for small children. All the writing prompts used in this study are argumentative in nature, and the study required the students to take a position and develop the argument to support their position. The writing prompts used in this study are shown in Appendix A.

\section{The second session}

Two weeks later, the second session was conducted. In this session, the students wrote another argumentative essay (original draft) in 40 minutes. The writing prompt asked them to argue whether city life or country life is better.

\section{The third session}

Two weeks later, the students participated in the third session for peer feedback training. Two class hours with a week in between were devoted to this training session. The session was carefully designed following Stanley's (1992) and Berg's (1999a) studies, in which it was found that systematic

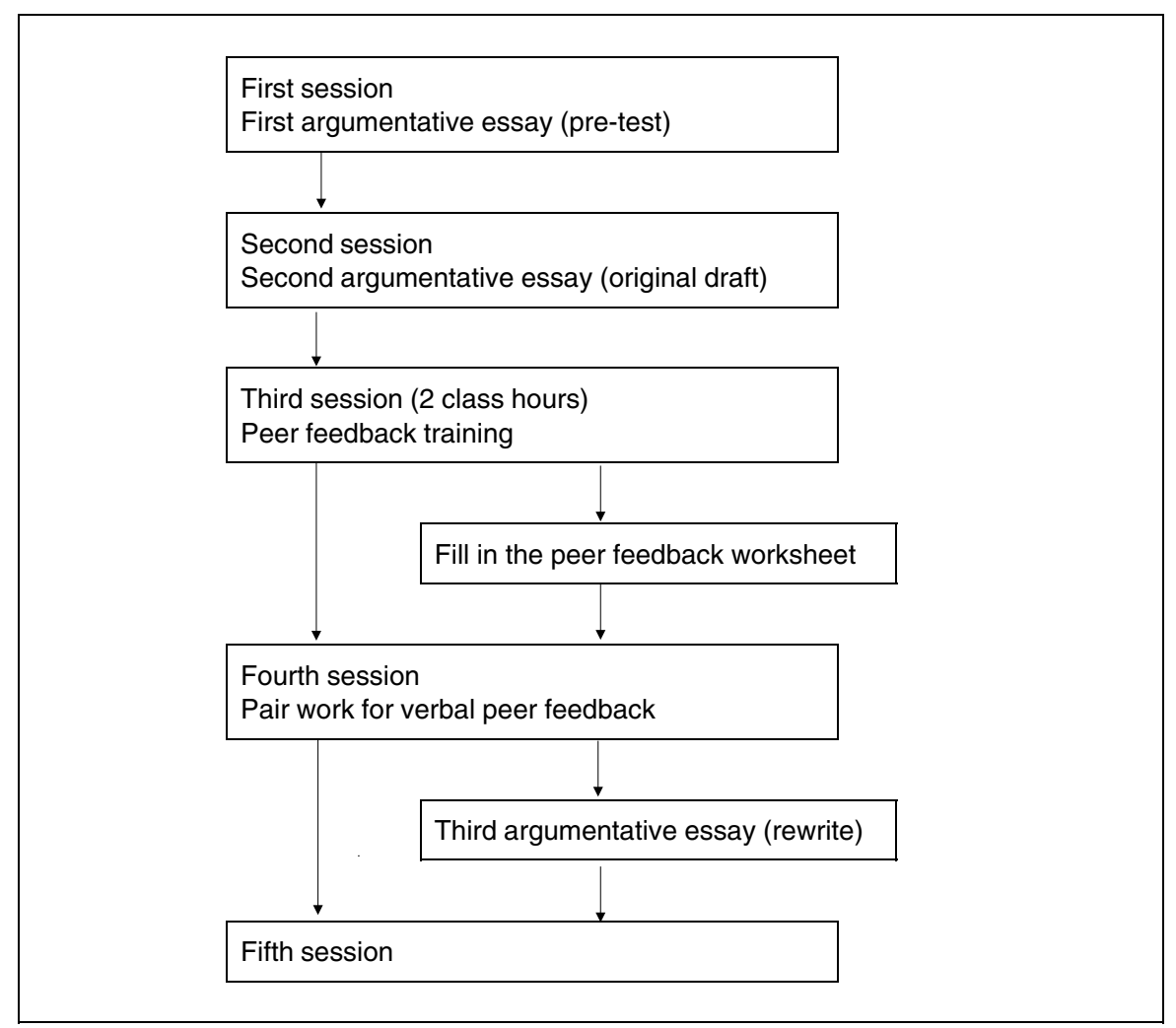

Figure 1. Research design. 
training in peer feedback resulted in L2 students' improvement of writing performance. The main focus of this training session was placed on global (audience, content, organization) as opposed to local (grammar, spelling, and mechanics) writing issues.

The training was conducted in three sections in the following manner. In the first section, the students first reviewed the organization of the English paragraph, which consists of a topic sentence, supporting sentences, and a concluding sentence. Then they reviewed how to use transition words that create coherence in a written text.

In the next section, each student was assigned a partner and told to work with this partner for the rest of the experimental sessions. This procedure was undertaken to foster rapport between the students working in pairs, a quality considered essential for effective peer feedback (Berg, 1999a, 1999b). Each pair was first given a series of sample passages, each containing a discourse-level problem such as lack of support or lack of unity; no grammatical errors were included in the passages. Appendix B shows the sample passages used in the training session. The students were told to identify the problem in each passage together and to provide suggestions to solve the problem. Then the whole class discussed what the most effective solution would be for each sample passage.

In the final section the students were given as a sample essay a copy of an argumentative composition written by a student enrolled in an EFL composition class the previous year. They were also given a "peer feedback worksheet," which was designed based on Berg (1999a, 1999b) and Blok (2000, personal communication). The worksheet consisted of two parts, the first of which was designed to lead the students to analyze the sample essay in terms of the basic structure of an English paragraph/essay. The second part asked the students to suggest how to improve the sample essay (see Appendix C). As in the second section, the students first worked as a pair and filled in the worksheet. Then all the students in the class exchanged their suggestions and discussed which could be more effective to improve the essay. Following this discussion, each student attempted to revise the sample essay by considering the suggestions discussed in class. As the last step for this session, each student was given his or her partner's essay produced in the second session (original draft) and another peer feedback worksheet. They were told to fill in the worksheet at home by using all the knowledge they had acquired during the peer training session and to bring the worksheet to the fourth session scheduled in a week. The students were allowed to use either English or Japanese in filling in the worksheet. The instructor told the students to focus on global macro-level issues rather than surface-level errors. 
The fourth session

In the fourth session, the students again worked with their partners, and the pair gave each other oral feedback by explaining what they had indicated on the peer worksheet. They were encouraged to ask questions of their peer whenever any comments were not clear to them. The instructor was especially careful to check whether any student assumed a hostile attitude, which is detrimental to successful peer feedback exchange (Nelson \& Murphy, 1992). After the students had finished making comments on the peer's essay, they were told to revise their own original essays at home by considering the peer comments provided on the worksheet and to submit the rewrites in a week. They were also given a peer response sheet (see Appendix D), which asked them to reflect on their partner's comments and to judge which suggestions they would accept or reject in revising their original draft. The peer response sheet also asked them to indicate how they incorporated the peer comments they accepted; for the comments they rejected, they were told to provide reasons for refusal.

\section{The fifth session}

After a two-week interval the students participated in the fifth and final session in which they wrote another argumentative essay as a post-test in which they argued whether early English education in Japanese elementary school is necessary.

\section{Analytic Measures}

\section{Holistic scoring}

In this study each student produced a total of four essays (pre-test, post-test, original draft, and rewrite). As a measure of overall quality, these essays were holistically scored by two raters on a scale of six points, with six as the highest score. One of the raters was an experienced Japanese EFL instructor who had a doctorate in English, and the other was a graduate student who was pursuing an MA in English and had experience in teaching English to junior high and high school students at a private school in Japan. The two raters first scored $10 \%$ of the total papers together in order to establish common criteria for judgment. Each then rated the rest of the papers independently, and then the two compared their scores. When any discrepancy in score occurred, they discussed their judgments until full agreement was reached.

\section{Word count}

As a measure of fluency, the number of words in each student's paper was also counted. 


\section{Classification of peer comments}

The comments on the peer feedback worksheet were carefully read in order to establish an appropriate classification system. The classification was conducted by two readers, who also served as raters for holistic scoring as explained above. As the initial step, following Berg (1999b), the first reader classified the comments roughly into meaning-based and form-based categories. She then further categorized these two types of comments into subgroups. Next, according to this tentative categorization system, she and the second reader independently classified the students' comments. The two readers discussed thoroughly any disagreement that arose. This discussion resulted in nine subgroups for the meaning-based category (unity, logical order, logical division, lack of support, quality of support, concluding sentence, coherence, sentence structure, and word choice) and two subgroups for the form-based category (grammar and mechanics). Categorization was thus derived inductively through careful reading of the students' comments. The percentage of the comments in each subgroup was calculated for A and B Classes respectively.

In addition, the students' reactions indicated on the response sheet were classified into two categories: accepted and rejected comments. The first category included peer comments that the students accepted and incorporated into their rewrites, whereas the second category included comments that they rejected and thus did not consider when revising. The ratios of accepted versus rejected comments were examined for each of the two classes.

\section{Data Analysis}

Each student's data were subjected to quantitative analysis and qualitative analysis as follows.

\section{Quantitative analysis}

1. Comparison between the pre- and post-tests

a. Holistic score (change in overall quality)

b. Number of words (change in fluency)

2. Comparison between the original and the rewrite

a. Holistic score (change in overall quality)

b. Number of words (change in fluency)

3. Peer comments

a. Number of comments

b. Number of meaning-based and form-based comments

c. Number of different types of peer comments

d. Number of accepted and rejected comments 


\section{Qualitative analysis}

a. Comparison of original drafts and rewrites by high-proficient students

b. Comparison of original drafts and rewrites by low-proficient students

\section{Quantitative Analysis}

The quantitative analysis of the study was fourfold. First, to answer the first research question (whether peer feedback has different effects on the writing performance of the Japanese EFL students with high and low English proficiency), $t$-tests were used to examine whether there were any changes in overall quality for A Class A and Class B. To avoid a possible Type 1 error $^{1}$ for the holistic scores in the pre- and post-tests produced by the students in A Class and B Class, Bonferroni adjustment was made in comparing the preand post-test scores for each of the two groups. The same statistical analysis was employed for the numbers of words in the pre- and post-tests written by A and B Classes in order to examine the differential effects of peer feedback on the two groups' fluency.

The second quantitative analysis was conducted to answer the second research question: whether peer feedback has different effects on the highand low-proficient students' revision. As in the first quantitative analysis, to examine the degrees of growth in overall writing quality, $t$-tests with Bonferroni adjustment were employed to compare the holistic scores given to the original and revised drafts produced by A Class and B Class. To investigate the gain in fluency, the same analytical procedure was undertaken for the numbers of words produced in the original and the rewritten essays for the two groups.

The next analysis was attempted in response to the third research question, which inquired about the kinds of peer comments made by the students with high and low levels of English proficiency. First, the number of peer comments indicated on the peer feedback worksheet was counted for the students in A Class and B Class. Next, the percentages of the meaning-based and form-based peer comments indicated by the two groups were calculated and compared with each other. Then the percentages of comments in the nine meaning-based and the two form-based subcategories were calculated for each group. Finally, the ratios of the accepted and rejected comments for the two groups were compared.

\section{Qualitative Analysis}

An in-depth comparative analysis of each student's original draft and rewrite was attempted in order to trace some intricate qualitative changes exhibited between the two writings that could not be captured by the formal quantitative statistical analyses. The qualitative analysis was conducted to 
address the fourth research question, which aimed to explore whether there were any conspicuous patterns in the relationship between the comments and revisions that characterized the high- and low-proficient students respectively.

\section{Results and Discussion}

\section{Quantitative Analysis}

Comparison between the pre-and post-tests. Figure 2 shows the change in mean holistic score between the pre- and post-tests for the students in A Class and B Class. The $t$-tests conducted with a Bonferroni adjustment showed significant differences in holistic scores between the pre- and post-tests for both A Class $(t=-6.80, p<.01)$ and B Class $(t=-8.07, p<.01)$. Figure 3 exhibits the change in the number of words between the pre- and post-tests for the students in A and B Class. The two classes revealed no significant difference in number of words between the two tests $(t=-1.88, p>.025$ for A Class; $t=-2.28, p>.025)$.

These results suggest that the students in both A Class and B Class exhibited significant improvement in overall quality in the post-tests over the pre-tests. However, the students in A Class with the high proficiency level demonstrated greater improvement than their B Class counterparts. The higher English proficiency level of the students in A Class might have enabled them to internalize what they had learned in the peer training session as well as in the peer feedback session and to use this internalized knowledge in producing the post-tests. On the other hand, due to their limitation in English proficiency, it seems that not all the students in B Class succeeded in using the knowledge they had gained through peer feedback training sufficiently in the post-tests. Although neither A Class nor B Class manifested a significant level of growth in fluency, it should be noted that the mean numbers of words for both the classes' post-tests were larger as compared with those of their pre-tests (158.92 vs. 199.08 for A Class and 105.17 vs. 139.83 for B Class).

Thus peer feedback seems to have moderate, if not strong, effects on both the high- and low-proficient Japanese students' writing fluency. Actual samples of pre- and post-tests written by a high- and low-proficient students are shown in Appendix E.

\section{Comparison Between the Original Drafts and the Rewrites}

Figure 4 shows the change in holistic score between the original drafts and the rewrites for A Class and B Class. The $t$-tests with Bonferroni adjustment revealed that the students in both classes demonstrated a significant positive change between the original drafts and the revised versions $(t=-2.72, p<.025$ for A Class; $t=-4.69, p<.01$ for B Class). Interestingly, the students in B Class 


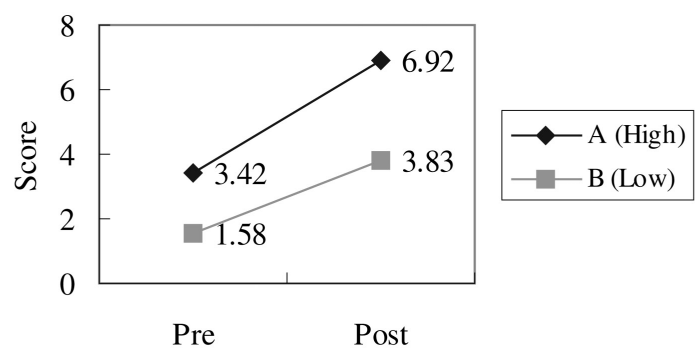

Test

Figure 2. Change in overall quality between pre-and post-tests.

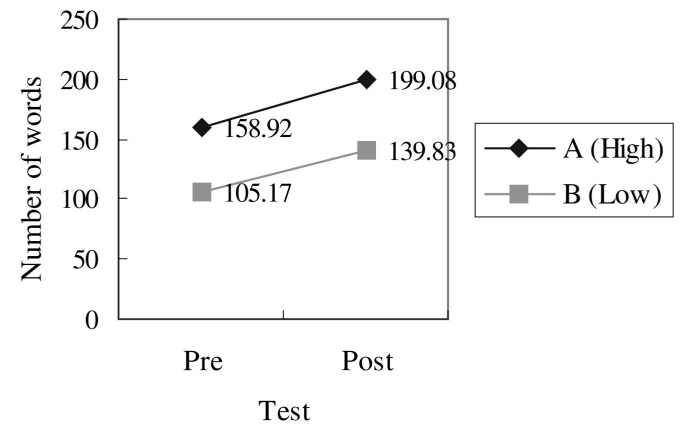

Figure 3. Change in fluency between pre- and post-tests.

with low English proficiency exhibited greater qualitative improvement than their counterparts in A Class.

With regard to the number of words, the $t$-tests with Bonferroni adjustment showed a significant difference between the original drafts and rewrite for B Class $(t=-2.71, p<.025)$, but not for A Class $(t=-2.16, p>.025)$.

Several reasons can be pointed out for these findings. First, the drafts produced by the low-proficient students had more room for improvement in terms of both overall quality and fluency than those by their high-proficient counterparts. However, more important, revising the original drafts by referring to each of the specific comments given by the peers might not have been a difficult task for the students with low proficiency. These low-proficient students seemed to need concrete comments that targeted specific portions of the text that needed revising. 


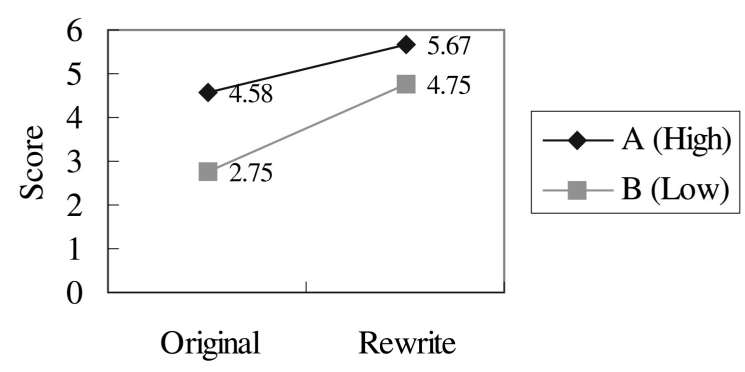

Draft

Figure 4. Change in overall quality between pre-and post-tests.

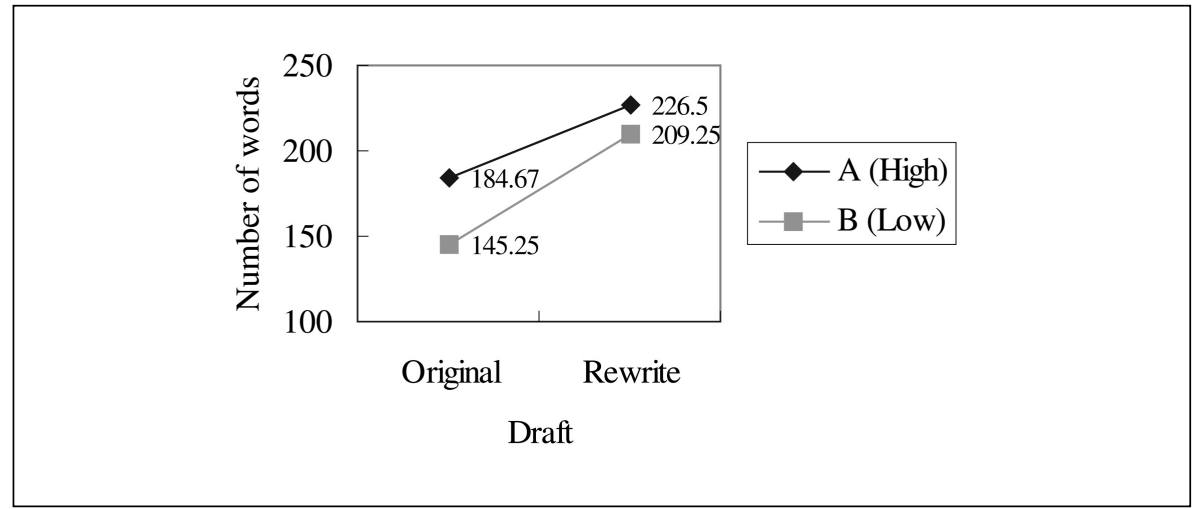

Figure 5. Change in fluency between original drafts and rewrites.

\section{Peer Comments}

Number of types of peer comments. The students in A Class made a total of 32 peer comments, whereas those in Class B made 54. Thus the students in the latter class produced significantly more peer comments than those in the former $(t=2.49, p<.05)$. This might have resulted from the drafts written by the students in B Class having more problems. Furthermore, unlike the students in Class A, whose comments were more global in nature and addressed to the whole discourse structure of the essays, those in Class B tended to make specific comments that focused on particular parts or sentences of the essays (see "Quantitative Analysis" for more details). This tendency of the low-proficient students might have led them to generate a greater number of peer comments.

Ratio of meaning-based and form-based comments. The great majority of the students' comments fell into the meaning-based categories. The meaning-related comments outnumbered the form-related ones for both A Class $(90.62 \%$ vs. $9.38 \%$ ) and B Class ( $94.44 \%$ vs. $5.56 \%$.) 


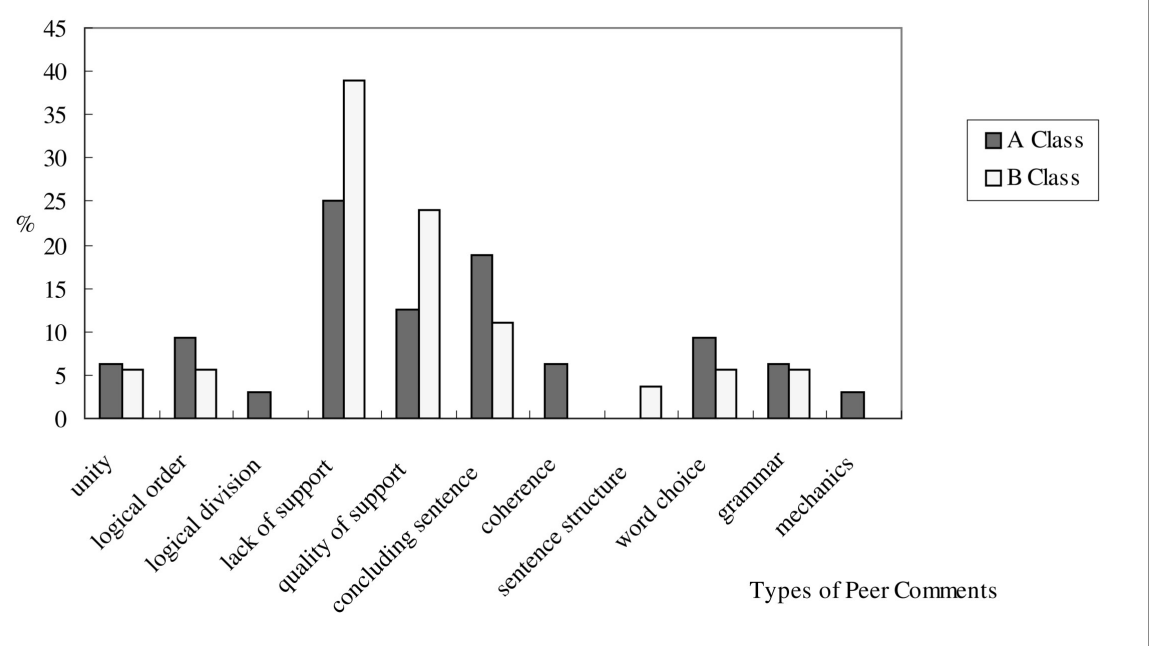

Figure 6. Ratio of different types of peer comments for $A$ and $B$ classes.

The chi-square test revealed no significant difference in the distribution of the two types of comments between the two classes $\left(\chi^{2}=1.17, p>.05\right)$. In the present study, both the high- and low-proficient students were mostly concerned with meaning-related features of writing; moreover, even the lowproficient students were not preoccupied with micro-level features such as grammar and mechanics.

Ratio of different types of meaning-based and form-based comments. Figure 6 summarizes the percentages of different types of comments made by the students in A and B Classes. The two groups exhibited a similar pattern in making peer comments $\left(\chi^{2}=12.16, p>.05\right)$. The comments made most frequently by the two groups fell into the category labeled lack of support. Both the high- and low-proficient students seemed to find in the peers' compositions a lack of support to substantiate the argumentative position presented at the outset. In contrast, neither of the two groups paid much attention to such features as sentence structure, grammar, spelling, or punctuation. Thus as this result suggests, if preliminary peer training is provided, EFL students might not be preoccupied with grammatical or orthographical correctness, but rather could focus on more global, discourse-level features of writing.

Accepted and rejected comments. The students in both A Class and B Class accepted most of the peer comments: $93.75 \%$ for Class A and $98.15 \%$ for Class B. No significant difference was observed in the ratio of accepted and rejected comments between the two groups of students $\left(\chi^{2}=1.17, p>.05\right)$. The students in the two groups both appreciated the comments from their peers and attempted to incorporate the comments into their rewrites. 


\section{Qualitative Analysis}

The following section reports on the results of the qualitative analysis, showing examples of actual comments made on the original drafts by the peers and how these comments were incorporated or not incorporated into the rewrites. The results of the qualitative analysis in this section are reported in the manner of case studies in order to clarify what strategies the students employed as readers who needed to make peer responses, and simultaneously as writers who made revisions to improve the original writing. All grammatical and spelling errors in sample essays are left intact. The sample comments and responses, both originally made by the students in Japanese, were translated by the author and are presented in English in this section.

\section{Comparison of Sample 1A (Original Draft) and Sample 1B} (Rewrite) by a High-Proficient Student in Class A

Samples 1A and 1B were produced by a student in A Class, with high English proficiency. His peer made three comments on his original draft (Sample 1A). The italicized parts in the original indicate the specific points to which the peer comments referred, whereas those in the rewrite show the actual revisions that the writer made in response to the peer comments.

The first peer comment (which belongs to a meaning-based category unity) related to the logical inconsistency between the position that the writer had taken at the beginning and in the middle of the essay. The second comment suggested that he should include more details to support his argument for a country life (a meaning-based category lack of support). The final comment suggested that he should add more concrete details based on his own experiences as a city dweller to explain the negative side of urban life (also a meaning-based category lack of support).

\section{Sample 1A (original)}

(1)(2)In my opinion it is better to live in the country because to live in the city has a lot of problem. For example, chemical smog, air pollution etc. Those are very harmful for our health. And I think that the city is very noisy. There are many cars, trucks, buses, and pachinko-parlors! But in the country, there are a lot of green. So there are fresh air and very quiet.

(1)However, I cannot support everything about living in the country. I want to live between city and the country. Many companys are in the city, so if I live in the country and work there, those are far from the country and I have to take trains for many hours!

Now I live in Itabashi ward and I do want to live here forever because we have a lot of greens (I saw a wild raccoon dog!) and very near from Ikebukuro, Shinjuku etc. Here is the most suitable place for me, I think. (Holistic score: 4 points, Number of words: 165) 


\section{Peer comments}

(1) In your topic sentence, you say, "In my opinion it is better to live in the country ..." However, you say in the middle, "I cannot support everything about living in the country." You need to take one position and continue supporting country life.

(2) More details are necessary to support your topic sentence.

(3) Since you live in an urban city, it might be better to include some real problems you have actually experienced or found while living in a big city.

After careful consideration of these comments, the writer decided to accept them all in composing his rewrite (Sample 1B). With regard to his peer's first comment, he revised his draft by maintaining his proposition for a country life throughout his entire essay. In response to the peer's second comment, he added more details to support his argument by referring to his grandmother and his high school teacher, who enjoy their life in the countryside. Also, in response to the third comment, he included some specific examples of problems related to urban life such as asthma, bronchitis, and noise.

\section{Sample 1B (rewrite)}

In my opinion it is better to live in the country because to live in the city has a lot of problems. For example, chemical smog, air pollution, and water pollution etc. Those are very harmful for our health. (3)I know a lot of people who suffer from asthma or bronchitis. And I also think that the city is very noisy. (3)But this "noise" does not mean the noise caused by natural things (animals, birds etc.) but caused by cars, buses, trucks or pachinko-parlors! On the other hand, the country is very quiet and calm. (2)My grandmother lives in Kumamoto now, and there are a lot of greens, and we can hear birds singing and see a beautiful sky (there are a lot of stars shining beautiful).

(2) And, recently, we can go to the city more easily and faster. My high school's teacher lives in Ibaraki and she comes to school by limited express for an hour everyday. And more and more companies or factories have moved to the country out of the city. And big shopping centers have opened in the country too. So it is not hard to live in the country.

Finally, I want to live in the country and enjoy the rest of my life hearing birds singing. But nowadays, we have many environmental problems. So we have to pay more attention to our earth and maintain our nature.

(Holistic score: 6, Number of words: 234) 
Subject $A 10$ 's responses

(1)' Accepted: I tried to keep my position that supports country life. It took me two hours to reorganize the entire composition.

(2)' Accepted: I added more details to support the position that it is better to live in the country.

(3)' Accepted: I tried to make specific examples of problems involving in urban life (asthma, bronchitis, noise, etc.).

These sample essays are noteworthy because both the peer comments made on the original draft and the revision strategies exercised in response to these comments were of a global type on a discourse level. All three comments from the peer related to the meaning-based, textual level of writing; no comments on grammatical or local features were made. The revising strategies adopted as reactions to the peer responses were also global in nature. That is, Subject A10 rewrote his original by considering the essay as a whole and made a substantial revision by reorganizing it to maintain unity: he developed his argument for country life throughout his entire composition.

\section{Comparison of Samples $2 A$ (Original Draft) and Sample 2B}

(Rewrite) by a High-Proficient Student in Class B

Sample 2A and Sample 2B were written by a student in B Class with low English proficiency. The peer comments written on this student's original draft and her reactions to those comments show a pattern that is different from that demonstrated by Samples 1A and 1B discussed above.

\section{Sample $2 A$ (original)}

It is better to live in the city for several reason. First of all, I live to eat.

(1) There are many foods restaurant in the city. The restaurant is far from the country. If you live in Tokyo, you can get there immediately. But, if you live in the country, you have to drive a car about twenty-thirty minutes to get there. Another reason,

(2)I like trip. (3)There is many kinds of norimono [public transporation] in Tokyo. Because I live in Tokyo, I can go to everywhere easily. (4)Another reason, I like to go to shopping.

(5) There are many closes in the city department. (6) So I can get various of closes. (7)I think that I go the country sometimes. But I don't think that I live in the country everyday. (8) In conclusion, I like the city because it is very usefull.

(Holistic score: 3, Number of words: 142) 
Peer comments

(1) It might be better to emphasize the statement that city life is convenient after you wrote about restaurants.

(2) You mentioned, "I like trip." But this is not clear.

(3) Give several examples of transportation and also point our some merits of having a convenient transportation system.

(4) I understand that you like to go shopping. But shopping does not mean only buying clothes.

(5) It might be better to state that there are many department stores before you say, "There are many clothes in the department store."

(6) Give specific examples of "various clothes."

(7) Correct mistakes in the last sentences.

(8) Move the concluding sentence before the sentence that begins with "I think ..."

Of these eight, seven were meaning-related comments. The first comment (logical order) asked the writer to move the sentences to make an argument flow more naturally. The second response pointed out a sentence irrelevant to the topic sentence (unity). In the third comment, the peer suggested that the writer add examples of public transportation available in the city (lack of support), whereas in the fourth he mentioned that more supports were necessary to explain the word shopping (lack of support). The fifth comment told the writer to make his logic clearer by reformulating sentences (logical order). The sixth asked for more examples of "various clothes" (lack of support). The seventh was the only form-oriented comment, which required the writer to correct grammatical mistakes in the last sentence. The final comment suggested that the last sentence be moved to consolidate the conclusion (logical order).

\section{Sample 2B (rewrite)}

I think that it is better to live in the city for several reasons. First of all, I like to eat. There are many food restaurants in the city, while the country has no restaurant near by. (1)If you live in the country, you have to drive a car about twenty-thirty minutes to get there. But, if you live in the city, you can get there immediately. (2) Another reason is that I can go to everywhere immediately because the city are (3)many kinds of vehicle — train, subway, bus, ship, monorail, etc. Many lines run in the station of city and a train comes immediately. Moreover, since there are many other vehicles, you can go place by the best method. Another reason is that (4)I like buying clothes. (5) There are many department stores and shops in the city. So I can buy various clothes-(6)T-shirts, trousers, skirts, coat, etc. ... Moreover, because the department store and the shop are built in near, I can choose 
good and inexpensive clothes. (8)In conclusion, I like the city because it is very useful. (7) And I think that I want to go to the country sometimes, but I do not want to live in the country everyday.

(Holistic score: 7, Number of words: 201)

\section{Subject B8's responses}

(1)' Accepted: I moved the sentence starting with "if you live in the country ..." and put it before the sentence "But, if you live in the city ..."

(2)' Accepted: I deleted the sentence "I like trip," added another sentence "another reason is that I can go to everywhere immediately," and put it before "many kinds of public transportation."

(3)' Accepted: I included several examples of vehicles.

(4)' Accepted: Instead of saying that "I like to go to shopping," I wrote "I like buying clothes."

(5)' Accepted: I mentioned that there are many department stores in the city.

(6)' Accepted: I included several examples of clothes I often buy.

(7)' Accepted: I checked grammar in the last sentences.

(8)' Accepted: I moved the concluding sentence, and put it before "I think that I want to go to the country sometimes."

The writer considered each of these comments, accepting all of them and attempting to incorporate each of them into her rewrite. Considering the first comment from her peer, she moved the position of the sentence as specified and added sentences to emphasize the convenience of the urban as opposed to the rural area. In accordance with the second comment, to make a logical connection clearer, one sentence was deleted ("I like trip") and another was added ("another reason is that I like buying clothes"). In response to the third and sixth comments, she added several examples of public transportation that are available in the city and clothes that can be bought at a department store. With regard to the fourth and fifth comments, the ambiguous sentences were rewritten to clarify the meaning ("I like buying clothes" for the fourth comment, and "there are many department stores and shops in the city" for the fifth). In response to the seventh comment she corrected grammatical mistakes. Finally, she moved the last sentence in the original and added a concluding remark.

What characterized the comments made on the original draft in Sample $2 \mathrm{~A}$ is that they were specific and local in nature. Unlike the peer responses shown in Sample 1A, most of the comments shown in Sample 2A were within the sentence level and were not related to the whole discourse structure: some of the comments asked the writer to add or remove the sentence, whereas others requested reconstruction of the problematic senten- 
ces to make the meaning clear. The comments were specific enough that even a less proficient student could cope. Having read all these comments carefully, the writer accepted all of them and made every possible effort to incorporate each into her rewrite, which resulted in a revised composition that was much longer and of better quality than the original version.

The qualitative analysis thus disclosed the respective patterns of peer comments and revisions that were manifested by and characterize the highand low-proficient students.

\section{Conclusion}

This study explored the nature and effectiveness of peer feedback in Japanese university EFL writing classrooms. The findings of the study can be summarized as follows.

1. Peer feedback had a positive effect on both high- and low-proficient Japanese university EFL students' writing performance in terms of overall essay quality;

2. Peer feedback, however, had no significant effect on fluency for either the high- or low-proficient students, although both groups produced longer compositions in the post-test;

3. Peer comment brought significant improvement to the rewrites produced by the students with high as well as low English proficiency levels as compared with their original drafts;

4. Peer comments led the low-proficient students to produce longer rewrites compared with their original drafts, whereas the comments did not affect the high-proficient students' rewrites in terms of fluency;

5. Regardless of the levels of proficiency, most of the peer comments were meaning-based, most of which were related to support and details in the essay;

6. Both the high- and low-proficient students accepted almost all the comments; and

7. The high-proficient students tended to make global, discourse-level comments and to attempt more substantial revisions, whereas the low-proficient students tended to provide specific sentential comments and local revisions.

As discussed in the introduction, we have not yet reached consensus as to whether peer feedback works or does not work for ESL/EFL writers. Opponents of peer feedback have maintained that ESL/EFL writers are still struggling with language problems and that those from a non-Western rhetorical/cultural background, where harmony is emphasized, have considerable difficulty engaging themselves in peer feedback sessions in which participants' active negotiation is required (Mangelsdorf, 1992; Zhang, 1995). In this study, however, peer feedback was found to be significantly useful for the Japanese EFL student writers, who came from a non-Western rhetori- 
cal/cultural tradition. Also, it was found that not only the high-proficient students but also their low-proficient counterparts appreciated the benefits of peer response. This attests to Mittan's (1989) observation that "students whose writing is consistently average or even poor very often write the most thoughtful and helpful peer reviews" (p. 212).

The positive results observed in the present study could be attributed to the integration of preliminary training into the research design. As Stanley (1992) and Berg (1999a, 1999b) insist, preliminary training is a key that determines the success of the use of peer feedback in ESL/EFL writing instruction. The students in the present study were provided with ample training in how to provide feedback to their peers with the worksheets as an instructional aid. Throughout the training sessions the students worked with a fixed partner. This procedure seemed not only to encourage the students to exchange comments actively, but also to develop mutual rapport as a pair. Therefore, contrary to the findings in some of the past studies mentioned above, in this study harmony as a non-Western cultural trait did not hamper the peer feedback sessions, but rather promoted them. In addition, during the training sessions, emphasis was put on the macro-level features of composition. Due to this emphasis, both the high- and the low-proficient students might have made considerably more meaning-based comments than form-oriented ones. Thus it seems to be a prerequisite to give the students substantial preliminary training in using peer feedback in EFL writing instruction.

The present study, however, has several limitations. First, the topic chosen for the study may have influenced the results. The topic used in the present study, "An urban life versus a country life," might have been easy to write about, and also the resultant essays might have been rather easy to comment on. The effects of peer feedback might differ depending on what kind of writing prompt is given to students.

Second, the positive effects of peer feedback found in the present study could be applied only to an EFL context in Japan, where students can share their same native language, that is, Japanese, in peer review sessions. Actually, all the students in this study used Japanese when giving peer feedback, although they were allowed to use either English or Japanese to fill in the worksheet as well as to exchange oral comments. Because they could use their first language, they could give their comments and suggestions without much difficulty or hesitation. If they had had to use English for peer feedback sessions, they could not have given so many beneficial responses to their peers as were demonstrated in this study. The use of English might have particularly inhibited some students with low English proficiency from expressing spontaneous responses to their peers' writing.

Many studies that examine the effects of peer feedback in L2 have presented conflicting results. This may result from an insufficient under- 
standing of differences between ESL and EFL. Naturally, the EFL and ESL contexts would influence the effects of peer reviews on student writing.

Considering these limitations, future studies are needed to further investigate the effectiveness of peer feedback in the EFL writing classroom. Some examples of these studies might be:

1. A study that examines the effects of peer feedback on modes of written discourse other than argumentation,

2. A study that analyzes the relationship between students' motivation and the effects of peer feedback,

3. A study that investigates the effects of different types of peer dyads on students' writing performance, and

4. A study that compares the effects of peer reviews conducted in the students' native language and ESL/EFL.

More studies are needed before we can reach consensus on the usefulness and effectiveness of peer feedback in ESL and EFL writing classrooms, which vary in student populations, yet share the same goal, that is, to promote the students' growth in writing in English.

\section{Note}

${ }^{1}$ Because a Bonferroni adjustment was employed, the statistically significant level was set at $p<.025$ for each of the $t$-tests in this study. This level was derived by dividing the usual significant level of .05 by the number of the $t$-tests used for the analysis for the holistic scores and word count respectively.

\section{Acknowledgments}

I thank Takanori Murayama for his assistance in data analysis and Mitali Das for her helpful comments and suggestions. I am also grateful to anonymous reviewers for the careful reading and valuable comments on the earlier version of this article. This study was supported by Senshu University Individual Research Fund, 2003.

\section{The Author}

Taeko Kamimura is a professor in the Department of English in Senshu University, Japan, where she teaches EFL composition and applied linguistics. Her interests include L1 influences on L2 writing, academic writing in EFL in a Japanese context, and the development of high school and college EFL writing textbooks.

\section{References}

Allaei, S.K., \& Connor, U. (1990). Exploring the dynamics of cross-cultural collaboration in writing classrooms. Writing Instructor, 10, 19-28.

Berg, E.C. (1999a). Preparing ESL students for peer response. TESOL Journal, 8, 20-25.

Berg, E.C. (1999b). The effects of trained peer responses on ESL students' revision types and writing quality. Journal of Second Language Writing, 8, 215-241.

Carson, J.G., \& Nelson, G.L. (1994). Writing groups: Cross-cultural issues. Journal of Second Language Writing, 3, 17-30.

Carson, J.G., \& Nelson, G.L. (1996). Chinese students' perceptions of ESL peer response group interaction. Journal of Second Language Writing, 5, 1-19. 
Caulk, N. (1994). Comparing teacher and student responses to written work. TESOL Quarterly, 28, 181-188.

Chaudron, C. (1984). The effects of feedback on students' composition revisions. RELC Journal, 15(2), 1-14.

Clifford, J.P. (1981). Composing in stages: The effects of a collaborative pedagogy. Research in the Teaching of English, 15, 37-53.

Connor, U., \& Asenavage, K. (1994). Peer response groups in ESL writing classes: How much impact on revision? Journal of Second Language Writing, 3, 257-276.

de Guerrero, M.C.M., \& Villamil, O.S. (1994). Social-cognitive dimensions of interaction in L2 peer revision. Modern Language Journal, 78, 484-496.

Elbow, P. (1981). Writing with power. New York: Oxford University Press.

Gere, A.R., \& Stevens, R.S. (1985). The language of writing groups: How oral response shapes revision. In S.W. Freedman (Ed.), The acquisition of written language: Response and revision (pp. 85-105). Norwood, NJ: Ablex.

Hedgcock, J., \& Lefkowitz, N. (1992). Collaborative oral/aural revision in foreign language writing instruction. Journal of Second Language Writing, 3, 141-163.

Keh, C.L. (1990). Feedback in the writing process: A model and methods for implementation. ELT Journal, 73(4), 203-304.

Kroll, B., \& Vann, R. (1981). Exploring speaking-writing relationships: Connections and contrasts. Urbana, IL: National Council of Teachers of English.

Leki, I. (1990). Potential problems with peer responding in ESL writing classes. CATESOL Journal, 3, 5-19.

Liu, J., \& Hansen, J.G. (2002). Peer response. Ann Arbor, MI: University of Michigan Press.

Lockhart, C., \& Ng, P. (1995). Analyzing talk in ESL peer response groups: Stances, functions, and content. Language Learning, 45, 605-655.

Mangelsdorf, K. (1992). Peer reviews in the ESL composition classroom: What do the students think? ELT Journal, 46, 274-284.

Mangelsdorf, K., \& Schlumberger, A. (1992). ESL student response stances in a peer-review task. Journal of Second Language Writing, 1, 235-254.

Mendonça, C.O., \& Johnson, K.E. (1994). Peer review negotiations: Revision activities in ESL writing instruction. TESOL Quarterly, 28, 745-769.

Mittan, R. (1989). The peer review process: Harnessing students' communicative power. In D.M. Johnson, \& D.H. Roen (Eds.), Richness in writing (pp. 207-219), New York: Longman.

Nagasaka, A. (2000, September). Japanese students' reactions to and perceptions of feedback: Analyses of journal entries and questionnaires. Paper presented at Symposium of Second Language Writing, Purdue University, West Lafayette, IN.

Nelson, G., \& Carson, J. (1992). An L2 writing group: Task and social dimension. Journal of Second Language Writing, 1, 171-193.

Nelson, G.L., \& Carson, J.G. (1998). ESL students' perceptions of effectiveness in peer response groups. Journal of Second Language Writing, 7, 113-131.

Nelson, G.L., \& Murphy, J.M. (1992). An L2 writing group: Task and social dimensions. Journal of Second Language Writing, 1, 171-193.

Nelson, G.L., \& Murphy, J.M. (1993). Peer response groups: Do L2 writers use peer response comments in revising their drafts? TESOL Quarterly, 27, 135-141.

Nystrand, M. (1984). Learning to write by talking about writing: A summary of research on intensive peer review in expository writing instruction at the University of Wisconsin-Madison, Urbana, IL. (ERIC Document Reproduction Service No. ED 255914)

Nystrand, M. (1986). The structure of written communication: Studies in reciprocity between writers and readers. Orlando, FL: Academic Press.

Rothschild, D., \& Klingenberg, F. (1990). Self and peer evaluation of writing in the interactive ESL classroom: An exploratory study. TESL Canada Journal, 8(1), 52-76. 
Spear, R. (1988). Sharing writing: Peer response groups in English classes. Portsmouth, NH:

Poynton/Cook.

Stanley, J. (1992). Coaching student writers to be effective evaluators. Journal of Second Language Writing, 1, 217-233.

Tompkins, G. (1990). Teaching writing: Balancing process and product. New York: Merrill.

Tsui, A B M., \& Ng, M. (2000). Do secondary L2 writers benefit from peer comments? Journal of Second Language Writing, 9, 147-170.

Villamil, O.S., \& de Guerrero, M.C.M. (1996). Peer revision in the L2 classroom: Social-cognitive activities, mediating strategies, and aspects of social behavior. Journal of Second Language Writing, 5, 51-75.

Villamil, O.S., \& de Guerrero, M.C.M. (1998). Assessing the impact of peer revision on L2 writing. Applied Linguistics, 19, 491-514.

Zhang, S. (1995). Reexamining the affective advantage of peer feedback in the ESL writing class. Journal of Second Language Writing, 4, 209-222.

\section{Appendix A}

\section{Writing prompts}

1. For the first essay (pre-test)

Some people argue that television is harmful for small children. Others argue that it is beneficial for them. Which position do you support? Give specific reasons and examples to support your answer.

2. For the second (original draft) and third essay (rewrite)

Some people argue that it is better to live in the country than in the city. Others believe that it is better to live in the city than in the country. Which position do you support? Give specific reasons and examples to support your answer.

3. For the fourth essay (post-test)

Some people argue that it is necessary to teach English to young elementary school students in Japan. Others argue that teaching English is unnecessary for young elementary school students. Which position do you take? Give specific reasons and examples to support your position.

\section{Appendix B}

Sample passages used in the peer feedback training session

1. Sample passage 1 (lack of support)

Our family trip to Costa Rica last summer was very exciting. Every day we saw something new and different. One day we went hiking, which was really an incredible experience. Another day we took a rafting trip down a river. We saw lots of unusual plants and animals that we had never seen before. We did many things that we will never forget. (From Blanchard, 1997)

2. Sample passage 2 (no clear topic sentence and concluding sentence) Britons end certain words with -se, whereas Americans usually end the same words with -ce (British practise versus American practice); the reverse is sometimes true, too (British defence versus American defense). Finally, most Americans consider neighbor a correct spelling, but a Briton characteristically adds a $u$ and spells the word neighbour. (Based on Araudet $\mathcal{E}$ Barrett, 1990)

3. Sample passage 3 (lack of unity) 
The Smithsonian Institute, located in Washington, D.C., has a dual purpose for the people of the United States. The first purpose is to do fundamental research. It then publishes the findings of this research. The second, and perhaps best-known, purpose is to maintain a group of museums. These museums are designed to preserve the history and culture of the U.S. Some of the most famous of these museums are the National Air and Space Museum, the National Gallery of Art and the National Museum of Natural History. The President of the United States also lives in Washington, D.C. These two functions of the Smithsonian Institute are very important to the American people. (From Frydenberg \& Boardman, 1990)

\section{Appendix C}

Peer feedback worksheet

Topic sentence

1. Is there any topic sentence? If so, write it down below:

2. Does the topic sentence clearly answer the assignment?

3. Does the writer take one position clearly in the topic sentence?

\section{Paragraph development}

1. Does the body of the paragraph give enough reasons to support the position that the writer has taken in the topic sentence?

2. Write down the major reasons that the writer gives in the body.

3. Is each reason fully explained?

4. Is there any part that is not related to main idea expressed in the topic sentence?

5. Is there any part that is not logically ordered and need to be moved around?

\section{Conclusion}

1. Is there any conclusion? Is so, copy it below.

2. Does the conclusion restate or summarize the topic sentence?

\section{Grammar}

Are there any major grammatical errors? Is so, circle those errors in the draft.

\section{Good points}

Tell the writer at least one thing you really liked about his/her writing.

\section{Suggestions for Draft 2}

List your suggestions to improve his/her writing. Your suggestions should be as specific as possible.

\section{Appendix D}

Peer response sheet

Please respond to each of the suggestions you received from the peer.

Which suggestions from the peer did you accept and which did you reject? For the 
suggestions you accepted, please explain briefly how you incorporated them into your revision. For those you rejected, please explain the reasons for your rejection.

(1) First suggestion

(2) Second suggestion

(3) Third suggestion

\section{Appendix E}

\section{Sample pre-and post-tests by a high-and low-proficient student}

1A. A sample pre-test by a high-proficient student in Class A

I support the latter. It is not good for eyes to watch TV for a long time. There are many stupid TV programs and they will give them bad influences. I also think it's waste of time to do nothing but watch TV lying on the sofa like couch potato all day long.

Of course it's convenient for us to get many informations through TV. We can get same informations through newspapers or books. But since the picture of the TV runs very fast, it's hard for us to remember the same picture if we moved to the pictures. On the contrary, we can keep pictures forever in the newspapers or books as words. We can look at the pictures and remember our impressions whenever we read newspapers or books.

(Holistic score: 2, Number of words: 130)

1B. A sample post-test by a high-proficient student in Class A I do not think that it is necessary to teach English to young elementary school students in Japan for several reasons.

First of all, I think teachers in elementary school should not shorten the time for teaching other subjects for English. If students study English, they cannot learn other subjects for long time. There are many important subjects like history, mathematics, science, music and art which they can study while they go to elementary school. Many of them may not have learned these subjects before they enter the elementary school. They must learn the basics of subjects except English. The second reason is that I think elementary school students should learn right Japanese. They are too young to speak right and beautiful Japanese. In addition, they have not known so many Japanese vocabulary yet. If they learn two different language when they do not have enough knowledge even about their native language, they will be at a loss. They may learn wrong Japanese and English because of chaos between these language. I think people cannot speak foreign language if they do not know their native language well. It is better for elementary school students to study only Japanese while they do not know about Japanese well. With these reasons, I support that it is unnecessary for young elementary school students to learn English. There plenty of time for them to master English even after the graduation from elementary school. They do not have to hurry to study English. (Holistic score: 8, Number of words: 248)

2A. A sample pre-test by a low-proficient student in Class B

I think that television is beneficial for children. And watching television is good for not only children but also everyone. Television gives us many influence. Watching $\mathrm{TV}$ is easier than reading newspaper. We put on television and we can get new 
things quickly than reading newspaper. Therefore children get bad things easily. But both bad thing and good thing are beneficial for children.

(Holistic score: 2, Number of words: 63)

2B. A sample post-test by a low-proficient student in Class B

I take a position that teaching English is necessary for young elementary school students for several reasons. First of all, society need a person who can speak and understand English because the grobalization is developing in the world today. In other words, foreigner will come into Japan to work for earn more and more. And Japanese will also go to foreign country to extend their job. They have to work together with foreigner. So it is important for elementary school student to study English as soon as possible. Another reason is that by studying English and speaking, children's vision change widely. Children can become international people. They will help Japan and even foreign country.

In conclusion, to study English at elementary school is necessary to make the international person.

(Holistic score: 6, Number of words: 129) 